\title{
Erratum to: Charcot-Marie-Tooth disease: genetic subtypes in the Sardinian population
}

Lorena Lorefice $^{1}$ - Maria Rita Murru ${ }^{2}$ Giancarlo Coghe ${ }^{1}$ Giuseppe Fenu ${ }^{1}$.

Daniela Corongiu $^{2} \cdot$ Jessica Frau $^{1} \cdot$ Stefania Tranquilli $^{2} \cdot$ Paolo Tacconi $^{3}$.

Alessandro Vannelli ${ }^{2}$ - Giovanni Marrosu ${ }^{2}$ - Elena Mamusa ${ }^{2}$ - Eleonora Cocco ${ }^{1}$.

Maria Giovanna Marrosu ${ }^{1}$

Published online: 7 April 2017

(C) Springer-Verlag Italia 2017

Erratum to: Neurol Sci (2017)

DOI 10.1007/s10072-017-2905-x

The author's given name and family name were initially interchanged inadvertently. The correct names have been corrected above. The original article was corrected.

The online version of the original article can be found at http://dx.doi. org/10.1007/s10072-017-2905-x

Lorena Lorefice

lorena.lorefice@hotmail.it

1 Multiple Sclerosis Centre, Department of Medical Sciences and

Public Health, University of Cagliari, Cagliari, Italy

2 Binaghi Hospital, ASL8, Cagliari, Italy

3 Institute of Neurology, AOU, Cagliari, Italy 